\title{
PODE O JUDICIÁRIO AGIR CONCRETAMENTE ALÉM DOS LIMITES DE SUA COMPETÊNCIA - ATIVISMO JUDICIAL E JUDICIALISMO DA POLÍTICA
}

\author{
Aline Fonseca Franco, José de Oliveira Costa Filho \\ Universidade do Oeste Paulista - UNOESTE. Curso de Direito, Presidente Prudente, SP. e-mail: \\ alinefonsecafranco@yahoo.com.br
}

\section{RESUMO}

O Estado Social Democrático e as normas programáticas previstas na atual Constituição, propiciaram aumento da demanda ao Judiciário, face ao estabelecimento de uma conscientização de direitos. Nesse cenário, somando-se a intensa produção legislativa, abre-se espaço para implemento de mudanças no Judiciário, verificadas pela alteração na forma de julgar anteriormente embasada na subsunção do fato à norma, passando a adotar critérios finalísticos de hermenêutica, com aplicação de princípios gerais de direitos. Surgem, assim, a judicialização do direito e o ativismo judicial. Diversas decisões nesses moldes foram emanadas pelo Judiciário, as quais alcançam efeitos em questões sociais e políticas. Tal posicionamento traz à tona discussões sobre legitimidade dessa atuação. O presente aborda o assunto, trazendo aspectos históricos e decisões apresentando posicionamentos favoráveis e contrários. Concluiu-se que não há como defender a total ausência de atuação do Judiciário, mas não é razoável uma interferência judicial demasiada, sob pena de afronta ao princípio republicano.

Palavras-chave: Judicialização, Ativismo Judicial, Legitimidade, República, Estado Social.

\section{CAN THE JUDICIARY ACT OF CONCRETE FORM BEYOND THE LIMITS OF ITS JURISDICTION - JUDICIAL ACTIVISM AND JUDICIALISMO POLICY}

\begin{abstract}
The Social Democratic State and the program law inserted in the current Constitution caused an increase in demand to the judiciary, according the establishment of an awareness of rights. In this scenario, adding to the intense legislative activity, open to implement changes in the judiciary, verified by the change in the form of subsumption judge previously grounded in the fact the norm, adopting finalistic criteria hermeneutics, applying principles general rights. Thus, arise judicialization of law and judicial activism. The judiciary issued various decisions along these lines, which achieve effects on social and political issues. This position brings up discussions about the legitimacy of this action. This addresses the issue by bringing historical aspects and decisions presenting pro and con positions. It was concluded that there is no way to defend the total absence of activity of the judiciary, but unreasonable legal interference too, otherwise affront to republican principles.
\end{abstract}

Keywords: Adjudication, Judicial Activism, Legitimacy, Republic, Social State. 


\section{INTRODUÇÃO}

As transformações sociais surgidas no mundo moderno e contemporâneo influenciaram de forma definitiva os rumos evolutivos do Direito que caminham para a aplicabilidade prática das normas.

É de se observar que o ambiente democrático permitiu maior informação e conscientização de seus direitos pelos cidadãos que passaram a buscar a proteção de seus interesses perante os tribunais e trouxe, como consequência, o aumento da demanda por justiça.

Cappelletti (1999) expõe que o cenário moderno constituído pelo Estado Social, pelas Constituições Programáticas, bem como pela intensa produção legislativa tornou campo fértil ao "direito judiciário" e à aproximação das duas grandes famílias do direito: "Common Law" e "Civil Law".

Segundo o autor, a expansão do direito legislativo na era moderna constituiu uma das principais causas do surgimento do "direito judiciário" ou "jurisprudencial" com o aumento do papel proativo dos juízes. Explica que o fundamento para tanto seria o fato de que as leis, ainda que bastante claras, sempre deixariam certa margem de interpretação do aplicador da lei. Assinala que as normas deixaram de regular basicamente condutas, fazendo surgir um novo modelo de legislação, com a introdução de normas mais abstratas e abertas, embasadas em princípios norteadores, sendo a regulamentação deixada para as normas infra legais e ao poder judiciário.

Assim, os juízes, compelidos a conferir efetividade à política programática, passaram a adotar uma posição mais concretista. E, nesse cenário, face ao ambiente propício à discricionariedade e subjetivismo, surgem as figuras da Judicialização do Direito" e do "Ativismo Judicial", as quais serão objeto de discussão no presente trabalho que visa abordar o assunto, trazendo aspectos históricos, definições, exemplos de decisões nesses moldes, apresentando também posicionamentos favoráveis e contrários a esta atuação concretista do poder judiciário.

\section{METODOLOGIA}

Para cumprir o objetivo proposto, o presente trabalho seguirá os métodos dialético-dedutivo, com emprego de pesquisa à legislação, doutrina e jurisprudência acerca da matéria objeto do estudo.

\section{ASPECTOS HISTÓRICOS - EVOLUÇÃO}

Uma rígida delimitação dos poderes de intervenção do Estado marcou o modelo liberal clássico, que primava pela liberdade individual. Marinoni (2008), cita que tal época sofreu influência do racionalismo, o qual impunha a afirmação do Direito pelo judiciário nos estritos limites do contido na lei. 
O autor expõe em sua obra os ensinamentos de Montesquieu para indicar como era na visão deste a aplicação do Direito pelo juiz, devendo a decisão judicial ser apenas um "texto exato da lei", atuando o juiz como a "bouche de la loi" (boca da lei). Nas palavras de Montesquieu:

“[...] não haverá também
liberdade se o poder de
julgar não estiver separado
do poder legislativo e do
poder executivo. Se
estivesse ligado ao poder
legislativo, o poder sobre a
vida e a liberdade dos
cidadãos seria arbitrário,
pois o juiz seria legislador.
Se estivesse ligado ao poder
executivo, o juiz poderia ter
a força de um opressor."
(MONTESQUIEU apud
MARIONI, 2008)

Teixeira (2002) também defende que esse modelo liberal fundamentava-se na aplicação do direito pelo silogismo subsuntivo, feito por meio da subsunção de fatos às normas.

Com o advento da crise da modernidade e da inefetividade dos direitos sociais, surgiram novas teorias da construção legislativa, as quais se distanciam do modelo defendido por Kelsen, para aproximar de novos métodos de interpretação das normas, adotando-se uma hermenêutica teleológica e finalística.

Observa-se, assim, maior aplicação dos Princípios Gerais de Direito, distanciando- se do mero subsumir-se dos fatos às normas para atribuir maior caráter prático e valorativo à norma face à demanda apresentada.

É nesse cenário atual, com a expansão do Poder Judiciário, que surge a discussão sobre o ativismo judicial e a judicialização do Direito.

\section{ATIVISMO JUDICIAL - JURISDIÇÃO DA POLÍTICA}

Segundo o jurista Elival Ramos (2010), deve-se entender o ativismo judicial como o exercício da função jurisdicional para além dos limites fixados pelo ordenamento que impõe, institucionalmente, ao Poder Judiciário fazer atuar, resolvendo litígios de forma subjetiva.

Saul Tourinho Leal (2008), por sua vez, assinala que essa expressão está associada à ideia de exorbitância de competência por parte do Poder Judiciário, razão por que adverte que chamar de ativista um tribunal implica atribuir-lhe algo de negativo na sua conduta institucional.

Luiz Roberto Barroso (2008) apresenta a seguinte definição para o ativismo judicial

[...] a ideia de ativismo judicial está associada a uma participação mais ampla e intensa do Judiciário na concretização dos valores e fins constitucionais, com maior interferência no espaço de 
atuação dos outros dois Poderes. (BARROSO, 2008)

Esclarece ainda Barroso (2008) que o ativismo judicial é uma forma de interpretar a Constituição de maneira a expandir o seu sentido e alcance, possibilitada, principalmente, pela omissão dos demais poderes. Reflete a maior participação do judiciário na consecução dos fins trazidos pela Constituição, interferindo de forma mais intensa no espaço de atuação dos demais poderes.

Em contrapartida, necessário observar que, diversamente do ativismo judicial, a "judicialização" seria o exercício regular da atividade judicial, na medida em que o direito positivado seria interpretado e aplicado no caso concreto, partindo-se do geral e abstrato para o particular e concreto, buscando a realização da justiça em sentido material.

Barroso (2008) faz a distinção entre judicialização e ativismo da seguinte forma:

A judicialização e o ativismo judicial são primos. [...] A judicialização, no contexto brasileiro, é um fato, uma circunstância que decorre do modelo constitucional que se adotou, e não um exercício deliberado de vontade política. Em todos os casos referidos acima, o Judiciário decidiu porque era o que lhe cabia fazer, sem alternativa. Se uma norma constitucional permite que dela se deduza uma pretensão, subjetiva ou objetiva, ao juiz cabe dela conhecer, decidindo a matéria. Já 0 ativismo judicial é uma atitude, a escolha de um modo específico e proativo de interpretar a Constituição, expandindo o seu sentido e alcance. Normalmente ele se instala em situações de retração do Poder Legislativo, de certo descolamento entre a classe política e a sociedade civil, impedindo que as demandas sociais sejam atendidas de maneira efetiva. A ideia de ativismo judicial está associada a uma participação mais ampla e intensa do Judiciário na concretização dos valores e fins constitucionais. (BARROSO, 2008)

Por fim, Barroso (2008) explica que essas críticas merecem reflexão, uma vez que a judicialização não poderá substituir a política, nem pode ser o meio ordinário de se resolverem as grandes questões. Pelo contrário, o Judiciário só deveria interferir quando a política falha.

\section{POSICIONAMENTO ATUAL DAS CORTES JUDICIAIS}

É de se notar que nos dias atuais o Poder Judiciário tem adotado postura mais concretista em suas decisões, entrando no âmbito de competência do poder legislativo, principalmente nos casos em que este se omitiu. 
Como exemplo, citam-se os posicionamentos do STF no Mandado de Segurança no 26602 e 26603 (perda do mandato eletivo por desfiliação partidária), no Mandado de Injunção no 788, (aposentadoria especial do servidor público); na decisão emanada na ADPF 45/DF (fornecimento de medicamentos pelo Estado), no decidido no mandado de injunção que conferiu o direito de greve aos servidores públicos civis, indicando a aplicação da consolidação de leis trabalhistas - CLT conferindo, pela primeira vez em sua existência, efeito concretista no referido remédio constitucional.

Verifica-se ainda atuação proativa do Pretório Excelso quando decidiu acerca de uniões homo afetivas, demarcação de terras indígenas, das cotas raciais, das pesquisas com células-tronco embrionárias, do nepotismo e da interrupção da gestação de fetos anencefálicos. Cita-se ainda a manifestação do STF em editar súmula vinculante para resolução de questões tributárias do ICMS surgidas pela concessão de benefícios fiscais de forma irregular pelos Estados.

Essas demandas foram levadas ao judiciário, uma vez que o legislativo se omitiu nessas questões políticas e sociais, por vezes em virtude de conveniência política.

O poder judiciário, como fundamento de legitimação de sua atuação vista como ativista, se ampara no princípio da inafastabilidade do controle jurisdicional com fundamento no art. 5ำ XXXV da Constituição Federal (CF).

Em relação a essa postura proativa, parte da doutrina tem defendido que o judiciário conta com legitimidade para invalidar decisões tomadas por representantes do poder legislativo. Luiz Roberto Barroso (2008) defende que essa prerrogativa tem alicerce na própria constituição, uma vez que os juízes não atuam em nome próprio, mas em conformidade com a lei e com autorização da Carta Maior. Portanto, ao aplicarem as normas estão reafirmando a vontade da maioria. Segundo o doutrinador, o ativismo presta-se como instrumento promotor da democracia.

Para essa corrente, qualquer juiz, com fundamento no princípio da inafastabilidade da jurisdição, tem o poder-dever de buscar a justiça no caso concreto e dar efetivação às normas programáticas e direitos sociais. Assim, deveria o juiz agir de forma proativa para dar concretude as suas decisões.

Defendendo o ativismo judicial, Hélder Fábio Cabral Barbosa (2011), expõe que:

Pensadores do direito podem se mostrar contrários ao ativismo judicial, sob a alegação de que um acréscimo de poder ao judiciário seria um 
desvio de finalidade, desvio do fim do judiciário, entretanto inexiste tal afirmação, uma vez que os juízes estariam apenas aplicando o direito, os direitos fundamentais em especial, direitos estes que gozam de autoexecutoriedade.

(BARBOSA, 2011)

Fernando Gomes de Andrade (2007), partidário da mesma corrente, ensina:

Cremos ser o Judiciário
competente para controlar
a legalidade de todo e
qualquer ato emanado pelo
poder público, seja
vinculado ou discricionário,
e ademais, o controle
político condizente com a
conveniência e
oportunidade - típicos do
administrador - deve de
igual modo ter sua
contingencia também
controlada pelo Judiciário
numa interpretação não
mais lógico-formal de suas
atribuições, mas em sentido
material-valorativo, ao
verificar se a medida
coaduna-se com os
princípios consagrados na
Constituição.
(ANDRADE,2007)

De forma contrária, outro grupo de doutrinadores, dentre ele Ana Paula de Barcellos (2008) criticam o ativismo judicial, principalmente quando as decisões invadem - controle de políticas públicas e o orçamento público.
De acordo com a autora, essa postura constitui uma intervenção do judiciário em matéria tipicamente reservada à deliberação política majoritária, sendo que uma intervenção do Direito no campo do pluralismo político constituiria grave desequilíbrio em prejuízo da democracia. Levaria também à pressuposição de que os juristas e juízes decidiriam de forma mais acertada que os legisladores em assuntos de políticas públicas, o que atacaria o princípio republicano. E, por fim, ressalta que outra crítica à essa postura residiria no fato de que os juízes não dispõem de elementos suficientes para avaliar a realidade estatal como um todo, uma vez que, atuando em casos concretos, o juiz ignora questões relevantes que demandam o gerenciamento de recursos escassos, levando a distorções na economia e no orçamento do país.

\section{É dessa forma que entende PEREZ} (2005), vejamos:

Não há dúvida que a abertura para o Poder Judiciário do exercício de um papel político favorece $o$ desenvolvimento do ativismo judicial. A transferência de decisões de repercussão política e social antes afetas ao Legislativo e ao Executivo à seara do Judiciário, facultalhe exorbitar no exercício de suas funções, infringindo os lindes demarcatórios das tarefas reservadas aos demais Poderes. $\mathrm{O}$ aumento quantitativo e qualitativo do 
controle judicial enseja aumento da possibilidade de desvirtuamento de suas funções. PEREZ (2005)

Também defensor desse

posicionamento, Fernando Facury Scaff (2008) destaca os efeitos negativos das decisões judiciais que interferem no campo financeiro do Estado, especialmente quando determinam o bloqueio judicial de verbas públicas ou atuam de forma a desconsiderar o planejamento público financeiro do governo executivo, vejamos:

Esta, a meu ver, é a pior fórmula que existe, pois destrói a possibilidade de planejamento financeiro público, e solapa a capacidade organizacional de qualquer governo. A alocação das verbas passa a ser determinada de forma pontual pelo Poder Judiciário, através de decisões individualizadas ou grupais, e não de forma global, como só pode ser feito através de normas leis, decretos, portarias e outros atos similares que compõem aquilo que se convencionou chamar de 'política pública' [...]. (SCAFF, 2008)

Somam-se também a essas críticas, o argumento de que o judiciário, ao conceder uma prestação a um particular, certamente estaria violando o direito de todos os outros, na medida em que confere um recurso escasso apenas aos que tiveram acesso à justiça.

\section{CONCLUSÃO}

Do exposto, conclui-se que o cenário apresentado pelas necessidades de concretização dos direitos sociais constitucionalmente garantidos, pela ineficiência dos poderes Executivo e Legislativo na realização de políticas públicas e no estabelecimento de normas para dirimir os conflitos sociais e políticos surgidos, abriuse espaço para o surgimento da judicialização do direito e do ativismo judicial.

Embora tenham vários entendimentos contrários ao Ativismo Judicial, não podemos deixar de sopesar que a sociedade não pode ficar ao alvedrio do legislador que se omite, por vezes por questões de conveniência política e, do Executivo, que deixa de dar efetividade às políticas públicas, levando o Judiciário a adentrar na competência alheia.

Ainda que seja dever do Judiciário atuar no caso concreto para o cumprimento desses direitos sociais, necessária também a análise quanto à competência para a definição das políticas públicas, bem como para o estabelecimento de normas em caráter geral, inerentes aos Poderes Legislativo e Executivo.

Por fim, diante de tantos argumentos contrários e favoráveis à atuação judicial na esfera dos demais poderes do Estado, verifica-se que não é possível adotar uma ou outra posição de forma radical, ou seja, não 
se pode defender a completa ausência de atuação do Poder Judiciário, mas também não seria razoável permitir uma interferência judicial demasiada, uma vez que poderia criar um "superpoder".

Assim, entendemos que, para o fortalecimento do princípio republicano e do restabelecimento da separação dos poderes, verifica-se a real necessidade de uma reforma política, de forma a superar a crise de representatividade e funcionalidade do Poder Legislativo, bem como seria necessário o aumento de mecanismos de controle da efetividade das políticas públicas pelo Executivo.

\section{REFERÊNCIAS}

ANDRADE, F. G. Considerações iniciais acerca do controle judicial concernente a concretização dos direitos fundamentais, sociais, prestacionais contidos na CF/88 Uma análise crítica da atuação do STJ e STF. In: SCAFF, F. F. (Coord.). Constitucionalismo, tributação e direitos humanos. Rio de Janeiro: Renovar, 2007.

BARCELLOS, A. P. Constitucionalização das políticas públicas em matéria de direitos fundamentais: o controle político-social e o controle jurídico no espaço democrático. In: SARLET, I. W.; TIMM, L. B. (Org.). Direitos fundamentais, orçamento e reserva do possível. Porto Alegre: Livraria do Advogado, 2008. p. 118.

BARBOSA, H. F. C. A efetivação e o custo dos direitos sociais: A falácia da reserva do possível. In: ANDRADE, F. G. (Org.). Estudos de Direito Constitucional. Recife: Edupe, 2011.
BARROSO, L. R. Judicialização, ativismo judicial e legitimidade democrática. 2008. Disponível em <http://www.oab.org.br/oabeditora/users/re vista/1235066670174218181901.pdf>.

Acesso em: 23 jul. 2014. p.6.

CAPELLETTI, M. Juízes Legisladores? Porto Alegre: Sérgio Antônio Fabris Editor, 1999.

LEAL, S. T. Ativismo ou Altivez? O outro lado do Supremo Tribunal Federal. Brasília: Instituto Brasiliense de Direito Público, 2008. $160 \mathrm{f}$.

MARINONI, L. G. Técnica processual e tutela dos direitos. 2. ed. São Paulo: Revista dos Tribunais, 2008.

PEREZ, C. A. N. Relação entre o ativismo judicial e a atuação deficiente do poder legislativo: altruísmo e desserviço da democracia. Revista de Direito Constitucional e Internacional, v.20, n.78, p.115-152, jan-mar. 2005.

RAMOS, E. S. Ativismo judicial. Parâmetros dogmáticos. São Paulo: Saraiva, 2010.

SCAFF, F. F. Sentenças aditivas, direitos sociais e reserva do possível. In: SARLET, I. W.; TIMM, L. B. (Org.). Direitos fundamentais, orçamento e reserva do possível. Porto Alegre: Livraria do Advogado, 2008. p.160161.

TEIXEIRA, J. P. A. Racionalidade das decisões judiciais. São Paulo: Editora Juarez de Oliveira, 2002.

Recebido para publicação em 17/08/2014 Revisado em 26/08/2014

Aceito em 28/08/2014 